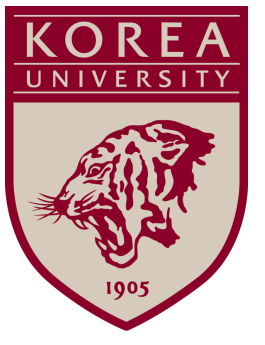

Discussion Paper Series

No. 1502

June 2015

\title{
Estimating Monetary Policy Rules When Nominal Interest Rates Are Stuck at Zero
}

Jinill Kim and Seth Pruitt

The Institute of Economic Research - Korea University

Anam-dong, Sungbuk-ku, Seoul, 136-701, South Korea, Tel: (82-2) 3290-1632, Fax: (82-2) 928-4948 Copyright (C) 2015 IER. 


\title{
Estimating Monetary Policy Rules When Nominal Interest Rates Are Stuck at Zero*
}

\author{
Jinill $\mathrm{Kim}^{\dagger}$ \\ Seth Pruitt \\ Korea University \\ Federal Reserve Board
}

June 2014

\begin{abstract}
Did the Federal Reserve's response to economic fundamentals change with the onset of the Global Financial Crisis? Estimation of a monetary policy rule to answer this question faces a censoring problem since the interest rate target has been set at the zero lower bound since late 2008. Surveys by forecasters allow us to sidestep the problem and to use conventional regressions and break tests. We find that the Fed's inflation response has decreased and that the unemployment response has remained as strong, which suggests that the Federal Reserve's commitment to stable inflation has become weaker in the eyes of the professional forecasters.
\end{abstract}

Keywords: monetary policy, policy rule, zero lower bound, survey data, market perceptions, censoring, Tobit, Blue Chip survey.

JEL codes: E53, E58.

*First draft June 2010. Previous drafts of this paper were circulated under the title "Forecaster-Perceived Monetary Policy Rules under the Zero Lower Bound." We thank Stefano Eusepi, Ryo Kato, Bae-Keun Kim, Andy Levin, Ricardo Nunes, Nick Turner, Yuchiro Waki, and Jonathan Wright for helpful discussions, as well as presentation participants at the 18th Australian Macroeconomics Workshop 2013, the University of Tokyo, the Bank of Japan, the 2012 Fall Meeting of the Japan Society of Monetary Economics, the 2011 Society for Nonlinear Dynamics and Econometrics Annual Symposium, the National Bank of Belgium, the Dutch National Bank, and the Federal Reserve Board. The views in this paper are solely the responsibility of the authors and should not be interpreted as reflecting the views of the Board of Governors of the Federal Reserve System or of any other person associated with the Federal Reserve System. The first author acknowledges the financial support from the National Research Foundation of Korea Grant funded by the Korean Government (NRF-2012S1A5A8024344).

$\dagger$ jinillkim@korea.ac.kr

${ }_{\ddagger}^{\ddagger}$ seth.j.pruitt@frb.gov 


\section{Introduction}

Did the (Global Financial) Crisis somehow alter the Federal Reserve's behavior? Since the 1990s, simple monetary policy rules for the nominal short rate have been widely used to analyze the behavior of central banks - most notably the Federal Reserve's behavior following Taylor (1993). The short rate is critical for the dynamics of the whole economy, not only by representing the reaction of a central bank to the current state of the economy but also by providing information of the economy's future to financial markets. Previous empirical literature such as Clarida, Gali and Gertler (2000) finds that the Federal Reserve's policy rule significantly changed around the singular event of high U.S. inflation at the end of the 1970s - we ask whether or not the singular event of the Global Financial Crisis has caused another such break in monetary policy. To empirically answer this question, an estimate of the policy rule depends on meaningful covariation between nominal short rates and economic fundamentals such as the inflation and unemployment rates. However, since December 2008 - shortly after the collapse of Lehman Brothers in September-Federal Reserve has been targeting its policy rate between zero and 25 basis points: U.S. nominal short rates have been stuck at their zero lower bound (ZLB). ${ }^{1}$ That is, policy rates are censored at zero and realized nominal short rates cannot provide the meaningful variation required to answer our research question. ${ }^{2}$

\footnotetext{
${ }^{1}$ In this paper, we assume that a nominal interest rate is effectively at its ZLB as far as it is below 25 basis points - see Bernanke and Reinhart (2004) for reasons why the short-term rate had better not be pushed down all the way to zero. In model simulations, the ZLB creates difficulty since it implies nonlinearity in the setting of monetary policy.

${ }^{2}$ This is our censoring problem: Even when both the rate recommended by a simple rule and so the desired target rate are negative, the ZLB-constrained target rate announced by the Fed stays weakly positive. See Rudebusch (2009) and Curdia and Woodford (2011) among others for the argument that desired target rates are negative. The censorship is with respect to the targeted policy rate, not the actual observed nominal short rate. We use the terms "policy rate" and "short rate" interchangeably in the remainder of the paper.
} 
A textbook way of tackling a censoring problem is to apply limited dependent variable methods to the historical data. However, as we illustrate below, these methods cannot define a powerful hypothesis test of whether or not policy response parameters changed because the short rate has always been censored since December 2008. The main idea of this paper is to avoid the censoring problem altogether by using data on agent expectations obtained from surveys of economic forecasts, and this paper attempts to answer whether or not Fed policy has changed since the Global Financial Crisis. Even while realized short rates were at the ZLB, one-year-ahead forecasts of the short rate stayed well above zero until August 2011, when a calendar-based forward guidance was introduced by the Federal Open Market Committee (FOMC). By using the one-year-ahead forecasts available in various issues of the Blue Chip Financial Forecasts and the Blue Chip Economic Indicators, we avoid the ZLB-induced censoring problem and estimate the Federal Reserve's post-Crisis monetary policy rule using conventional regression methods. No other paper, to our knowledge, has so straightforwardly evaluated the Federal Reserve's Taylor-type policy response function since the Crisis began. Therefore our results shed light on an important economic question that cannot be satisfactorily answered using conventional historical data.

In addition to providing one-year-ahead forecasts in each issue, some issues of the Blue Chip surveys include long-horizon forecasts of inflation, unemployment and short rate. We take these forecasts as data for respective long-run values of these variables; having data to discipline the inflation target and market-perceived NAIRU is a further advantage of using these forecast data. In contrast, conventional policy rule estimation using only historical data does not uniquely identify these values.

An intellectual price we pay for our simple solution to the ZLB-censorship problem is 
that the object estimated in this paper is market participants' perception of how the Federal Reserve sets policy. Nonetheless, such an object is interesting in its own right, as argued by Hamilton, Pruitt and Borger (2011). Our perspective is that it is important for economists to understand financial markets' perception of the Fed's behavior since the Global Financial Crisis. We discuss how this perceived rule is related to the rule estimated on historical data, during the pre-ZLB period during which both may be reliably estimated. Our results using forecast data broadly show that after the Crisis the Federal Reserve's perceived inflation response significantly decreased. Meanwhile, the Federal Reserve's perceived unemployment response remained strong or may even have strengthened a bit further.

In terms of central bank communication, our findings provide evidence that the Federal Reserve's commitment to stable inflation has become much weaker in the eyes of the professional forecasters - and probably the financial markets as well. This result could be interpreted as either bad (the loss of inflation-fighting credibility) or good (successful forward guidance), and we do not advocate one interpretation over the other. At the same time, professional forecasters view the Federal Reserve as firmly as ever, if not more, committed to closing the unemployment gap.

This paper touches on several strands of previous work. Taylor (1993) and Clarida, Gali and Gertler (2000) are the seminal references on constructing and detecting breaks in the Fed's policy rule using actual data. Hamilton, Pruitt and Borger (2012) instead estimate the market-perceived rule, as we focus on, using futures prices and lagged actual variables to instrument for market expectations. In the same vein, Ang, Boivin, Dong and Loo-Kung (2011) estimate a time-varying policy response using yield curve data which could also be viewed as capturing the market-perceived rule. Mitchell and Pearce (2010) use Wall Street 
economists' forecasts, and Carvalho and Nechio (2012) use consumers' forecasts to estimate the Fed's perceived policy rule. Fendel, Frenkel and Rulke (2011) use professionals' forecasts to estimate perceived policy rules in emerging markets. Survey data have also been used for structural estimation by Coibion and Gorodnichenko (2012) to assess informational rigidities, by Devereux, Smith and Yetman (2012) to assess cross-country risk-sharing on a panel of professionals' expectations, and by Hirose and Kurozumi (2012) to identify news shocks. None of the above papers analyze whether or not the Global Financial Crisis changed the Fed's monetary policy. Gerlach and Lewis (2011) assess if the Crisis affected the policy rule of the European Central Bank, and Swanson and Williams (2014) assess how the Crisis affected Treasury prices' response to data releases.

The plan of the paper is as follows. Sections 2 and 3 describe our data and estimation methods. In Section 4, we present our main results, analyze their robustness, and use our estimates to understand the forces which market forecasters believe shape Federal Reserve policy, as well as the effects of Federal Reserve communication on markets' beliefs. Section 5 concludes.

\section{Data}

The main idea of this paper is to use data on agents' expectations to answer our research question: Has the Fed reaction function changed since the Global Financial Crisis? A key advantage of such data is that they may forecast future economic conditions that warrant uncensored policy rates, even when actual short rates at the time of the forecast are stuck at the ZLB. This means that all the necessary ingredients - dependent and explanatory variables - retain meaningful variation that can be used to estimate the key policy response 
coefficients. In turn, we can in the usual manner form statisical hypothesis tests addressing our research question.

A brief digression on terminology may be helpful. This paper deals with two types of data. The first type of data we refer to as actual, historical or realized data are prices or measurements that actually prevailed in the U.S. experience. Examples are the Fed Funds rate during December 2005 or the unemployment rate measured by the Bureau of Labor Statistics (BLS) for December 2005 - these are actual, historical or realized data. The second type of data we refer to as expectations or forecast data are forecasts of future economic conditions. An example is the Fed Funds rate expected to prevail in 2006Q4, as forecasted in December 2005. Studies such as Ang, Bekaert and Wei (2007) suggest that surveys contain remarkably accurate forecasts, and we make the assumption that the survey data we use accurately represent market expectations.

\subsection{Historical Data Sources}

Our main historical data include the civilian unemployment rate from BLS, the ex-food/energy consumer price index (core CPI) from BLS, and 90-day U.S. Treasury bill rate from the Federal Reserve Board. In subsequent analysis, we also use two-year and ten-year U.S. Treasury bond yields from the Federal Reserve Board. We construct actual core-CPI inflation as the 12-month log growth rate in the core-CPI index. ${ }^{3}$

\footnotetext{
${ }^{3} \mathrm{CPI}$ excluding food and energy prices is used to measure inflationary pressures to which policy responds since it strips out price fluctuations (food and energy prices) that are typically considered temporary. Congruently, core-CPI inflation is a better forecaster of future CPI inflation than headline inflation itself. Hence we find it reasonable to associate realized core inflation (in the rule estimated on historical data) with expected headline inflation (in the rule estimated on forecast data).
} 


\section{$2.2 \quad$ Forecast Data Sources}

Our main forecast data source is the Blue Chip Economic Indicators and the Blue Chip Financial Forecasts. Collected monthly since the late 1970s, these surveys provide short-tomedium horizon (one- to six-quarter ahead) forecasts of the annualized percentage change in the CPI, the Fed Funds rate, and the unemployment rate. The forecasts we use are the median forecast from a panel of between 30 and 60 professional forecasters in the financial services, consultancy, and academic industries, with emphasis on forecasters in the financial services industry. ${ }^{4}$

The surveys are released by the 1st (for Blue Chip Financial Forecasts) and the 10th (for Blue Chip Economic Indicators) of the eponymous month but collected through the end of the previous month - therefore the "April 2000" survey actually represents information known to the market until the end of March 2000. Having forecasts for particular future quarters is important because we want to maintain a constant forecast horizon as much as possible. Strictly speaking, the forecast horizons vary by a couple of months since the surveys are monthly and forecast horizons are quarterly. ${ }^{5}$ For example, if we assign the quarterly value to the middle month, then the April 2000 survey contains a 2001:Q2 "four-quarterahead" forecast that is 13 months ahead, and the June 2000 survey contains a 2001:Q2 "four-quarter-ahead" forecast that is 11 months ahead.

Since our paper's main idea is to use professional forecasts to estimate professionals' perception of Federal Reserve policy response, we would like to maintain, as much as possible, a

\footnotetext{
${ }^{4}$ Using the full panel of forecasts would allow us to control for panel composition issues discussed by Engelberg, Manski and Williams (2011), but are only electronically available since 2001.

${ }^{5}$ Another popular survey data is the Survey of Professional Forecasters which is published quarterly. Romer and Romer (2000) examined Federal Reserve forecasts against these private forecasts.
} 
constant forecast horizon so as to minimize superfluous additional dimensions to the analysis. The fore mentioned data limitations prohibit us from strictly doing so, but we have found that these small differences in forecast horizon do not alter our results (in the pre-Crisis period during which we have a sufficient number of observations). Hereafter, we refer to the four-quarter-ahead forecasts of a month's survey as "one-year-ahead" forecasts.

Biannually the survey also publishes long-horizon forecasts (the five-year average, five years ahead) for these variables, which we convert to a monthly measure by linear interpolation. We use the Fed Funds rate as our primary policy measure so that we have both its medium- and long-horizon forecasts. We use CPI inflation and unemployment to represent inflation and activity pressures, respectively. We use data starting in 1986 when all variables are observed, and these series are plotted in Figures 1-3.

\subsection{Data Plots}

Figure 1 demonstrates the main idea of our paper. The solid line represents the one-yearahead forecast for the short rate, and this forecast remains above the ZLB even after December 2008 when the realized short rate (the dashed line) hits the ZLB. It is inconsequential to our exercise that this forecast indicates that market expectations exhibited serially correlated forecast errors after the onset of the Global Financial Crisis. What is important for our analysis is that the forecasts manifest a systematic relationship between short rate on

one side (the solid line in Figure 1) and inflation and unemployment on the other side (the solid lines in Figures 2 and 3).

The long-horizon forecast of the short rate, inflation rate and unemployment rate are plotted by the dash-dotted lines in Figures 1-3, respectively. Taking the difference between 


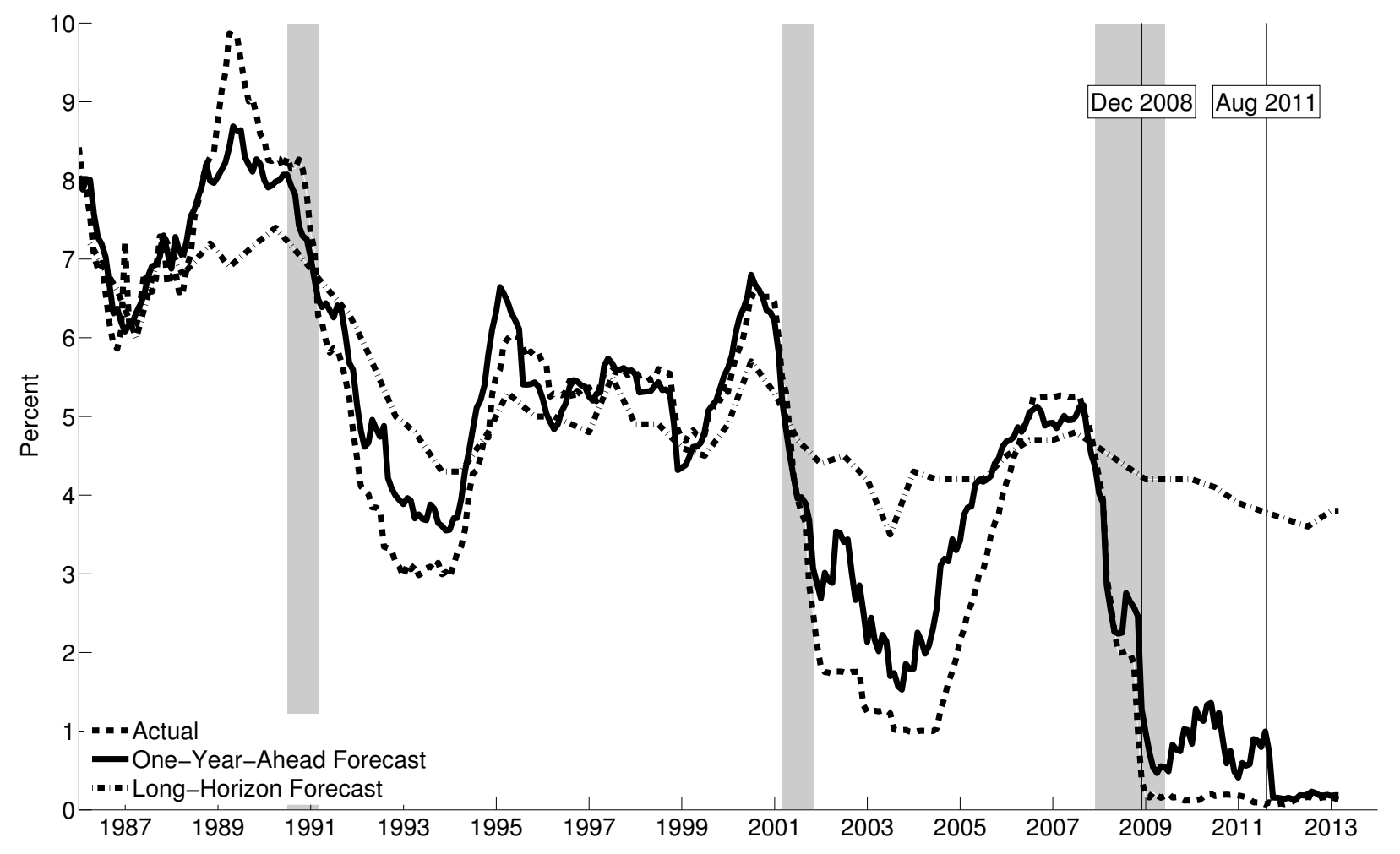

Figure 1: Short-Term Interest Rates

Notes: Data for January 1986 to February 2013. Actual values from the Federal Reserve Board, dashed line; median one-year-ahead forecast from Blue Chip Economic Indicators, solid line; long-horizon forecasts from Blue Chip Economic Indicators, dash-dotted line. Vertical lines are at December 2008 when the ZLB period began and at August 2011 when the FOMC introduced calendar-based forward guidance. Shaded are the NBER recession periods.

the long-horizon nominal-rate forecast and the long-horizon inflation-rate forecast yields the long-horizon real-rate forecast, based on the Fisher identity. Figure 1 shows the longhorizon forecasts of the short rate have trended down over the past three decades; much of this follows the fall in the long-horizon forecasts of inflation plotted in Figure 2. Meanwhile, the long-horizon forecast of the unemployment rate hovers around familiar values of five to six percent, in Figure 3.

Going back to Figure 1, its right tail demonstrates why we end our estimation sample in August 2011. At the August 2011 FOMC meeting, the Committee announced that "excep- 


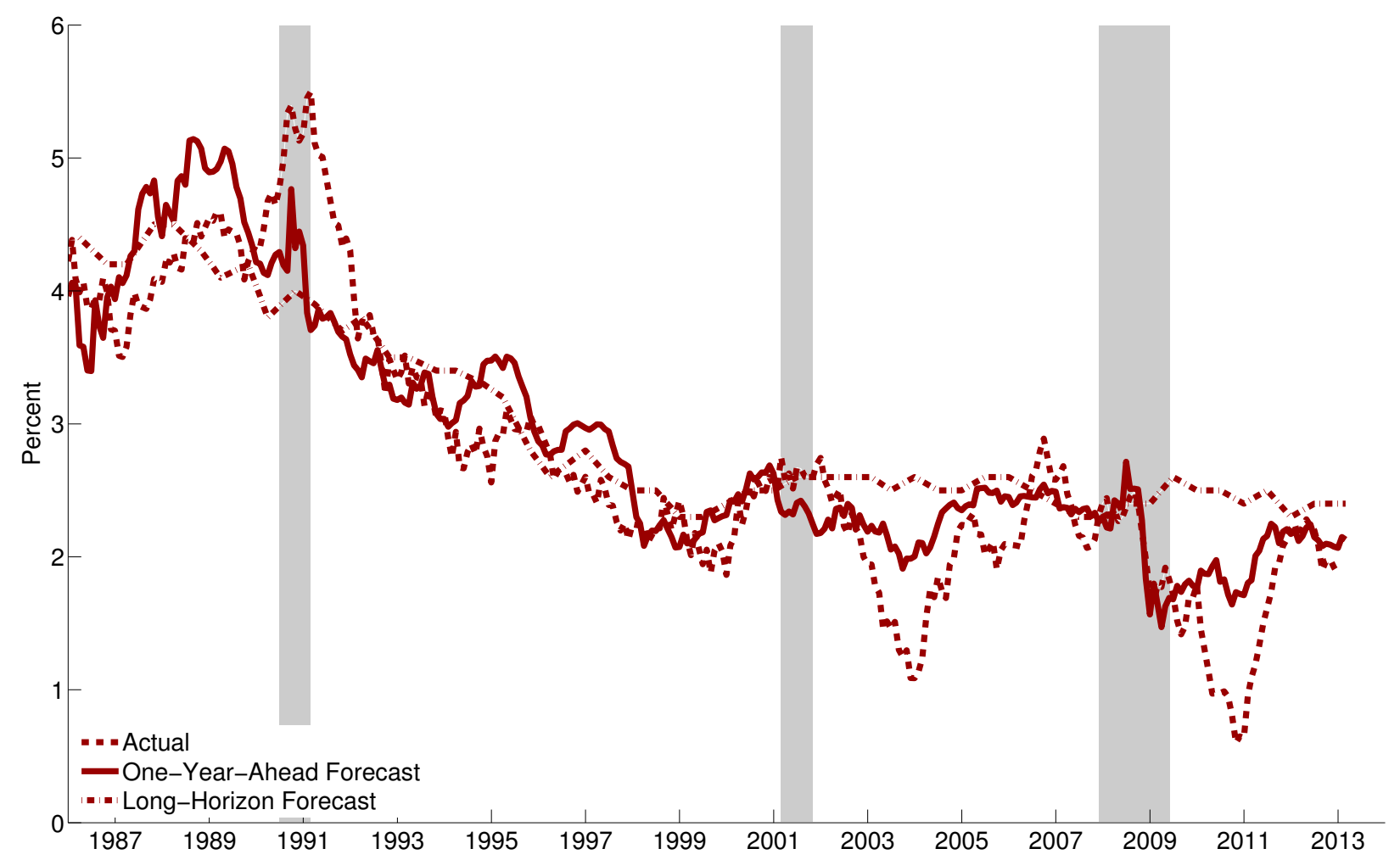

Figure 2: Inflation RATES

Notes: Data for January 1986 to February 2013. Core inflation from BLS, dashed line; median one-yearahead inflation forecast from Blue Chip Economic Indicators, solid line; long-horizon inflation forecasts from Blue Chip Economic Indicators, dash-dotted line. Shaded are the NBER recession periods.

tionally low" short rates would likely be held "at least through mid-2013." ${ }^{6}$ Our surveys — as well as price-based measures of market expectations such as Fed Funds futures or eurodollar contracts - respond immediately to this policy statement. Surveys published between September 2011 and the current draft (June 2014) exhibit medium-horizon short rate forecasts at the ZLB. Therefore this paper investigates the evidence of a discrete change in the Federal Reserve's (perceived) policy response to inflation and unemployment using forecast data somewhere between the onset of the Global Financial Crisis and August 2011.

\footnotetext{
${ }^{6}$ Earlier, FOMC introduced the "extended period" language in March 2009, instead of "for some time". Subsequently, the Committee extended the calendar-based forward guidance to late 2014 in January 2012 and to mid-2015 in September 2012. In December 2012, FOMC switched to its new threshold-based forward guidance (regarding 6.5\% unemployment and 2.5\% inflation) instead of the calendar-based forward guidance.
} 


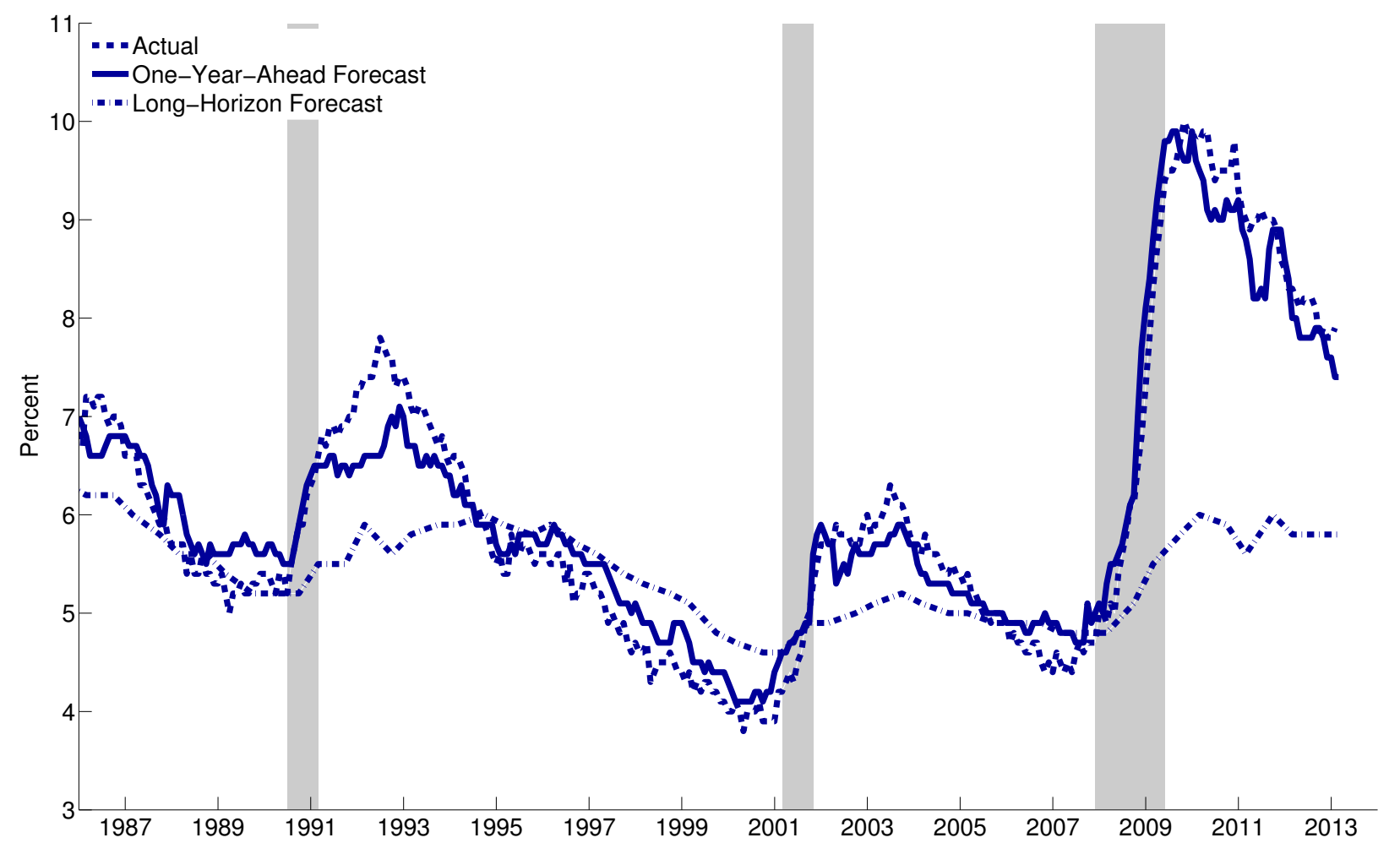

Figure 3: UnEMPLOYMENT RATES

Notes: Data for January 1986 to February 2013. Actual values from BLS, dashed line; median one-year-ahead forecast from Blue Chip Economic Indicators, solid line; long-horizon forecasts from Blue Chip Economic Indicators, dash-dotted line. Shaded are the NBER recession periods.

\section{Estimating Policy Rules}

This section begins by considering how policy rules are estimated on historical data. We note that there is an identification problem using historical data, in that the Federal Reserve's inflation target, non-accelerating inflation rate of unemployment (NAIRU), and the equilibrium real rate are unobserved. In this paper we solve the identification problem by assuming that long-horizon forecasts from the Blue Chip provide information about these variables. This leads to rules that are estimated using both historical and forecast data.

We then discuss how short rates have been censored by the ZLB since December 2008. 
We can use Tobit regression to deal with the censorship in obtaining full-sample parameter estimates. But Tobit, or any other limited dependent variable method, cannot deliver hypothesis tests of whether or not parameters changed exactly between uncensored (pre-ZLB) and censored (post-ZLB) observations. Therefore, we cannot use historical data to answer our main research question. This leads us to estimate rules using only forecast data. We end the section by illustrating our econometric methodology.

\subsection{Historical and Forecast Data}

To represent the the Federal Reserve's reaction to economic fundamentals, the popular Taylor-type policy rule specification is

$$
i_{H, t}=r_{t}^{*}+(1-\beta) \pi_{t}^{*}+\beta \pi_{H, t}+\delta\left(u_{H, t}-u_{t}^{*}\right),
$$

where the subscript $t$ corresponds to the monthly frequency of the data and $H$ indicates that these are historical data values. This specification follows, among others, Boivin (2006) in using unemployment to measure real activity. It is similar in spirit to rules using the output gap — as in Taylor (1993) — and reflects the limitations of our survey data. The policy rate $i_{t}$ responds to the inflation response coefficient $\beta$ times the deviation of inflation $\pi_{H, t}$ from its long-run target $\pi_{t}^{*}$; the unemployment response coefficient $\delta$ times the deviation of unemployment $u_{H, t}$ from the non-accelerating inflation rate of unemployment (NAIRU) $u_{t}^{*}$. When both inflation and unemployment are at their long-run values of $\pi_{t}^{*}$ and $u_{t}^{*}$, the nominal short rate converges to the economy's equilibrium real rate $r_{t}^{*}$ plus inflation $\pi_{t}^{*}$ as implied by the Fisher identity. The *-variables are written with $t$ subscripts to allow for time variation in the Federal Reserve's inflation target or the Federal Reserve's estimates of the NAIRU and real rate. We allow for such time variation for the simple reason that these 
estimates - as evident from past published Federal Reserve Greenbook forecasts - vary over time.

We do not include the lagged policy rate in (1). Rudebusch (2006) argues against including the lagged rate, instead identifying serially-correlated policy rule residuals as the source of persistence in policy rates. We follow suit. In Section 4.2 we find evidence that the risk premium significantly explains the serially-correlated policy rule residuals estimated in forecast data. We take this to suggest that market participants perceive that Federal Reserve policy responds to risk conditions, as has been argued by Atkeson and Kehoe (2009), in addition to inflation and real activity.

The existing literature predominantly implements equation (1) using historical data. An obvious problem is that the ${ }^{*}$-variables - the inflation target, the equilibrium real rate, and the NAIRU - are typically unidentified by the historical data. What is typically estimated (e.g. Clarida, Gali and Gertler (2000)) is the reduced form

$$
i_{H, t}=c_{0}+c_{1} \pi_{H, t}+c_{2} u_{H, t}
$$

Note that $c_{1}=\beta$ and $c_{2}=\delta$ but $c_{0}=r_{t}^{*}+(1-\beta) \pi_{t}^{*}-\delta u_{t}^{*}$ which highlights the identification problem: The intercept term is a function of the unobserved *-variables and the response parameters $\beta, \delta$. But then estimating a constant $c_{0}$ amounts to assuming that the ${ }^{*}$-variables above are constant (or else the knife-edge case that any variation in any two *-variables exactly offsets variation in the remaining ${ }^{*}$-variable). Assuming that the ${ }^{*}$-variables are constant is demonstrably inaccurate from the Federal Reserve's published forecasts; even under the constancy assumption, we cannot uniquely determine the three constant long-run forecasts. This is what we label the "identification problem." 
To solve this problem, we simply assume that long-horizon forecasts from the Blue Chip surveys represent the market's estimate of the Federal Reserve's inflation target, NAIRU, and real rate. When we estimate policy rules on the historical-forecast data combination, we impose that the ${ }^{*}$-variables in (1) come from the forecast data. This assumes that market participants understand historical monetary policy through the lens of actual historical values of inflation and unemployment and their best forecasts of the Federal Reserve's inflation target, NAIRU and real rate estimates. This carries the advantage of solving the identification problem by disciplining it with observables.

\subsection{Only Forecast Data}

Using long-horizon forecast data solves the identification problem. But since December 2008, policy rule estimation using historical data has run into the "ZLB problem." That is, the policy rule we want to understand is that describing the Federal Reserve's target short rate, varying in response to economic conditions. But in December 2008 the nominal short rate hit its effective lower bound of zero, and therefore the Federal Reserve cannot set the target short rate at the level - presumably negative, as argued for example in Rudebusch (2009) and Curdia and Woodford (2011) — warranted by economic conditions.

The ZLB problem is one of censoring, and in principle, censoring can be handled by running a limited dependent variable regression, such as a Tobit regression. However, the nature of our censoring problem is peculiar. An important group of observations - those immediately following the Global Financial Crisis - are all censored. Thus we can, and will, run a Tobit regression to appropriately address the censorship to produce full-sample parameter estimates. 
But the Tobit, or other similar frequentist methods, is not able to provide reasonable hypothesis tests of whether or not parameters are different between censored and uncensored observations. To make this concrete, suppose we place our break at December 2008. Likelihood ratio tests of the break require a maximum likelihood post-break estimate. But this estimate is based only on censored observations and cannot be consistent (for example, premises of Newey and McFadden 1994 Theorem 2.1 cannot be satisfied). Therefore, historical data cannot be used to understand whether, in the wake of an unprecedented Global Financial Crisis, the Federal Reserve's short rate policy rule has changed or not. ${ }^{7}$

This leads us to use even more of the forecast data in order to answer our main research question. The forecast-data-based rule we estimate is

$$
i_{F, t}=r_{t}^{*}+(1-\beta) \pi_{t}^{*}+\beta \pi_{F, t}+\delta\left(u_{F, t}-u_{t}^{*}\right) .
$$

Equation (2) only differs from (1) in that the subscript $H$ is replaced by $F$ : (2) takes forecasts as data.

We assume that our median-forecast data reveal the representative forecaster's conditional expectation. For example: $i_{F, t}$ is the month $t$ expectation of the short rate that will prevail during the quarter one year after month $t ; \pi_{t}^{*}$ is the month $t$ belief of the Federal Reserve's inflation target. Therefore, variables with the $F, t$ subscript do vary at a monthly frequency (from survey to survey), but pertain to a quarterly time period about one year in the future, as discussed in Section 2.

\footnotetext{
${ }^{7}$ The Federal Reserve has undertaken unconventional monetary policy, involving large-scale asset purchases, to face the fact that short rates cannot be further lowered. Kim and Pruitt (2013) related how negative the prescribed short rate is to how big the asset purchases would be. Analysis of the policies and effects of such unconventional monetary policy is very interesting and would complement our focus on the conventional method of monetary policy implementation through the lens of the short rate.
} 


\subsection{Estimation Methodology}

The standard Tobit model (e.g. Amemiya, 1985) applies to our framework for either kind $K \in\{H, F\}$ of data:

$$
\begin{gathered}
i_{K, t}=\left\{\begin{array}{lll}
\tilde{i}_{K, t} & \text { if } & \tilde{i}_{K, t}>0 \\
0 & \text { if } & \tilde{i}_{K, t} \leq 0
\end{array}\right. \\
\text { where } \\
\tilde{i}_{K, t}=r_{t}^{*}+(1-\beta) \pi_{t}^{*}+\beta \pi_{K, t}+\delta\left(u_{K, t}-u_{t}^{*}\right)
\end{gathered}
$$

Here $\tilde{i}$ is the target policy rate we believe is structurally related to the Taylor rule on the RHS of (3). However, we only observe $i-i$ equals $\tilde{i}$ when $\tilde{i}$ is positive, but otherwise $i$ equals zero and $\tilde{i}$ is censored. The likelihood function is given by

$$
\begin{aligned}
L= & \prod_{t<t_{Z L B, K}} \sigma^{-1} \phi\left[\left(i_{K, t}-r_{t}^{*}-(1-\beta) \pi_{t}^{*}-\beta \pi_{K, t}-\delta\left(u_{K, t}-u_{t}^{*}\right)\right) / \sigma\right] \\
& \times \prod_{t \geq t_{Z L B, K}}\left(1-\Phi\left[\left(r_{t}^{*}+(1-\beta) \pi_{t}^{*}+\beta \pi_{K, t}+\delta\left(u_{K, t}-u_{t}^{*}\right)\right) / \sigma\right]\right)
\end{aligned}
$$

for $\phi, \Phi$ the density and distribution functions of the normal distribution.

For historical data, the period $t_{Z L B, H}$ (December 2008) corresponds also to a break point whose significance we would like to test. From (4) it is clear that we cannot obtain consistent estimates of the parameters on the $t>t_{Z L B, H}$ data $-i_{K, t}$ does not appear at all in the postbreak likelihood! On the other hand, in forecast data the period $t_{Z L B, E}$ (August 2011) is after the breakpoint $t_{Z L B, H}$ and the post-break likelihood includes uncensored observations and therefore could produce a test statistic of the break's significance.

\section{Estimation Results}


Table 1 reports the results of several specifications. They use either, as detailed immediately above, the historical-forecast data combination or only forecast data. For exposition's sake, we consider two sample periods: a 1986-2008 sample that ends before the ZLB period, and the full 1986-2013 sample.

Panel A includes ordinary least squares estimates using the historical-forecast data combination, which are provided to show the need for limited dependent variable methods - the main point is that including the ZLB-censored observations mechanically shrinks both $\beta, \delta$ estimates towards zero. In Panel B, we consider Tobit regression results using the historicalforecast data combination that appropriately handles censoring. In neither Panel A nor B, however, do we test for a break in $\beta$ or $\delta$ because it is inappropriate to do so - in the case of Panel A because there is unaccounted-for censoring of the data, and in the case of Panel $\mathrm{B}$ because there are only censored observations after the ZLB break date which means the post-break parameter estimates are inconsistent. Therefore, we turn in Panel C to Tobit regression results using the forecast data - not only the long-run expectations but also the one-year-ahead forecasts - which both appropriately handles the censoring and allows for meaningful hypothesis tests.

\subsection{Parameter Estimates}

Panel A of Table 1 presents results from an ordinary least square estimation using the historical data while the intercept term is disciplined by the long-run forecasts of each variable. ${ }^{8}$ For the sample of 1986-2008, the estimated responses are consistent with the conventional numbers associated with such a rule. The inflation coefficient of 1.358 is insignificantly dif-

\footnotetext{
${ }^{8}$ Recall that an OLS regression with only historical data yields the identification problem of not being able to interpret the intercept coefficient.
} 
Table 1: Policy Rule Parameter Estimates

\begin{tabular}{|c|c|c|c|c|}
\hline & Inflation & Activity & Inflation & Activity \\
\hline & \multicolumn{2}{|c|}{ A. OLS, Historical and Forecast Data } & \multicolumn{2}{|c|}{ B. Tobit, Historical and Forecast Data } \\
\hline $1986-2008$ & $\begin{array}{c}1.358 \\
(0.186)\end{array}$ & $\begin{array}{c}-1.402 \\
(0.149)\end{array}$ & $\begin{array}{c}1.358 \\
(0.186)\end{array}$ & $\begin{array}{l}-1.402 \\
(0.149)\end{array}$ \\
\hline $1986-2011$ & $\begin{array}{c}0.967 \\
(0.245)\end{array}$ & $\begin{array}{c}-0.943 \\
(0.098)\end{array}$ & $\begin{array}{c}1.384 \\
(0.302)\end{array}$ & $\begin{array}{c}-1.454 \\
(0.198)\end{array}$ \\
\hline pre-ZLB & $\begin{array}{c}1.358 \\
(0.234)\end{array}$ & $\begin{array}{c}-1.402 \\
(0.131)\end{array}$ & $\begin{array}{c}1.358 \\
(0.656)\end{array}$ & $\begin{array}{c}-1.402 \\
(0.442)\end{array}$ \\
\hline ZLB & $\begin{array}{l}-0.242 \\
(0.911)\end{array}$ & $\begin{array}{l}-1.170 \\
(0.292)\end{array}$ & $\begin{array}{c}1.275 \\
(2.626)\end{array}$ & $\begin{array}{l}-4.668 \\
(2.324)\end{array}$ \\
\hline & \multicolumn{2}{|c|}{ C. Tobit, Only Forecast Data } & \multicolumn{2}{|c|}{ D. OLS, Only Forecast Data } \\
\hline $1986-2008$ & $\begin{array}{c}1.5 \overline{50} \\
(0.187)\end{array}$ & $\begin{array}{c}-0.786 \\
(0.138)\end{array}$ & $\begin{array}{c}1.550 \\
(0.187)\end{array}$ & $\begin{array}{c}-0.786 \\
(0.138)\end{array}$ \\
\hline $1986-2011$ & $\begin{array}{c}1.500 \\
(0.212)\end{array}$ & $\begin{array}{l}-0.681 \\
(0.069)\end{array}$ & $\begin{array}{c}1.500 \\
(0.212)\end{array}$ & $\begin{array}{l}-0.681 \\
(0.069)\end{array}$ \\
\hline pre-ZLB & $\begin{array}{c}1.550 \\
(0.215)\end{array}$ & $\begin{array}{c}-0.786 \\
(0.124)\end{array}$ & $\begin{array}{c}1.550 \\
(0.215)\end{array}$ & $\begin{array}{c}-0.786 \\
(0.124)\end{array}$ \\
\hline ZLB & $\begin{array}{l}-0.019 \\
(0.990)\end{array}$ & $\begin{array}{l}-0.960 \\
(0.254)\end{array}$ & $\begin{array}{l}-0.019 \\
(0.990)\end{array}$ & $\begin{array}{l}-0.960 \\
(0.254)\end{array}$ \\
\hline Break $p$-value & 0.081 & 0.258 & 0.203 & 0.451 \\
\hline
\end{tabular}

Notes: Monthly data from the Federal Reserve Board, BLS, and Blue Chip surveys, January 1986 to August 2011. In the Inflation or Activity columns, estimates are reported for $\beta$ or $\delta$, respectively - two estimates are reported for regression specifications allowing for a break in policy parameters. Block bootstrapped standard errors are provided in parentheses underneath the point estimates. The pre-ZLB period is January 1986 to November 2008, the ZLB period is December 2008 onwards. Panels C and D include "Break $p$-value" for the test that either $\beta$ or $\delta$ does not break at the onset of the ZLB. For the Tobit model in Panel C, this is a likelihood ratio test distributed $\chi^{2}(1)$. For the OLS model in Panel D, this is a $F$ test distributed $\chi^{2}(1)$.

ferent from the 1.5 number typically associated with the Taylor rule. Regarding the response to real activities, the typical coefficients with respect to the output gap are 0.5 or 1.0. Transforming these numbers using a conventional Okun's law coefficient of 2, we come up with conventional coefficients for unemployment being at -1 or -2 . Our estimated coefficient of 
-1.402 in Panel A lies within this range. ${ }^{9}$

When we apply the same OLS methodology to the 1986-2011 data including the ZLB period, the estimated coefficients of 0.967 and -0.943 are subject to the censoring problem. The absolute values of the two coefficients are smaller than the previous sample, reflecting the feature that the LHS variable is censored at zero during the ZLB period starting late 2008. For example, the inflation coefficient during the latter subsample corresponding to the ZLB period has a negative sign.

There are many standard ways of limited dependent variables that can resolve such censoring problems. The estimation results provided in Panel B are based on a Tobit regression for the same dataset that is used for Panel A. Since that data between 1986 and 2008 are not censored, the Tobit regression yields the identical point estimates to the OLS regression. Unlike OLS, the Tobit regression appropriately handles censored data - as shown in the row for the 1986-2011 sample that includes the ZLB period. Though the coefficients are not as tightly estimated as the shorter sample without ZLB, the estimated coefficients are broadly consistent with the conventional numbers. The problems of high standard errors can be more clearly seen for the results based on the latter subsample corresponding to the ZLB period: The standard errors are 2.626 and 2.324. Since the LHS variable varies so little due to censoring, the estimated coefficients do not contain much information. For our research question, we cannot test whether the behavior of the policy function has changed around the start of the zero lower bound.

While Panels A and B use historical data for the interest rate and the other variables,

\footnotetext{
${ }^{9}$ If we do not use the long-run forecasts and assume instead that the steady-state values for the real rate, the inflation rate, and the unemployment rate are 2.25, 2.5, and 5.75, respectively, the coefficients for inflation and unemployment are 1.56 and -1.2 .
} 
Panel $\mathrm{C}$ of Table 1 is based on the one-year-ahead forecasts for the interest rate and the other variables. The estimation results for the 1986-2008 sample indicate that the inflation response is marginally stronger and that the activity response is slightly weaker than those in Panels A and B. For our main research question of how the monetary policy reaction has changed around when the policy rate entered the zero lower bound, the subsample results indicate that the response to inflation became much weaker than before the ZLB (from 1.55 to a slightly negative number, with two numbers being different at the $10 \%$ significance level) and that the reaction to real activities got stronger after the Global Financial Crisis (from -0.786 to -0.960$)$.

Panel D is based on OLS results with the one-year-ahead forecasts as data, which confirms that the forecast data is not censored and an OLS would yield the same estimation results as the Tobit regression.

\subsection{Understanding the Residuals}

The solid line of Figure 4 represents the residuals from our preferred specification using forecast data only. ${ }^{10}$ As previously mentioned, in a conventional policy rule regression with historical data, residuals are often interpreted as capturing policy "shocks." However, in our benchmark rule using (2) with forecast data, the residuals represent a shift of expected policy that is not accounted for by a linear combination of inflation and unemployment forecasts. We find a few features noteworthy. First, Greenspan's chairmanship starting in mid-1987 was characterized by reasonably small residuals until around 2001. This means that forecasters believed that short rates largely reflected economic conditions according to

\footnotetext{
${ }^{10}$ As mentioned above, our inference is robust to serial correlation in the residuals. Figure 4 makes it clear that this robustness was required.
} 


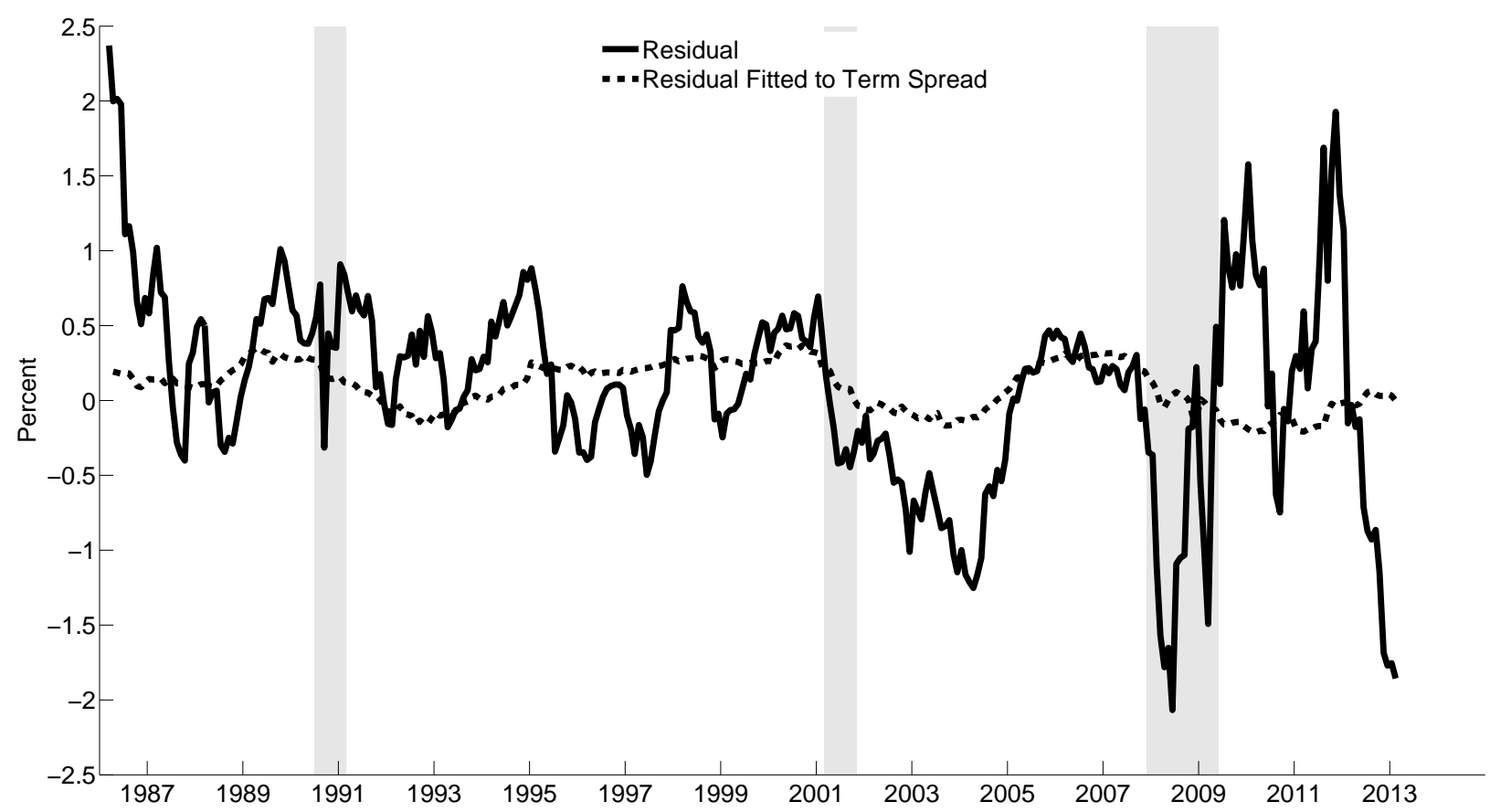

Figure 4: Residuals of the One-Year-Ahead Short-Rate Equation

Notes: Monthly data from Blue Chip Economic Indicators, median forecasts, January 1986 to February 2013. Residuals from Tobit allowing for breaks in $\beta, \delta$ in Panel $\mathrm{C}$ of Table 1 , plotted as solid line. Dashed line is fitted value of regression of the residual on the actual U.S. term spread (10y-2y). Shaded are the NBER recession periods.

a simple Taylor rule.

In the first half-decade of the 21st century, the residuals are persistently negative. This implies that market professionals during this time expected more expansionary policy than would otherwise be called for by economic conditions. Starting in 2005 the expected expansionary boost is steadily removed, and by the time of Bernanke's chairmanship starting in early 2006 the residuals are nearer to zero.

As the Global Financial Crisis begins, the residuals become sharply negative through early 2009 and then are largely positive from 2009-2013 until most recently moving sharply down again. This suggests that market professionals saw Federal Reserve policy as much more expansionary than warranted by inflation and unemployment as the 2007 recession got 
under way. As the Global Financial Crisis began as early as 2007, it appears that private forecasters perceived that the Federal Reserve was responding to more than a typical Taylor rule arguments.

What have market participants perceived, apart from inflation and real activity, drives short rates policy? One way to answer this question is to explain these residuals variation. Atkeson and Kehoe (2009) argue that "business cycle movements of the short rate arise as a result of the Fed's endogenous policy response to exogenous business cycle fluctuations in risk." Hence, we will check if the residuals are related to forecasters' perceived risk. ${ }^{11}$ We proxy for risk by the term spread, defined as the difference between 10-year and 2-year bond yields, a common measure financial market risk at a business cycle frequency. ${ }^{12}$ This exercise takes forecasted short-rate policy that is orthogonal to forecasted inflation and forecasted real activity and explains the unexpected part using a measure of financial risk.

A regression of the residuals on the term spread shows a strong connection that is both economically and statistically significant: The coefficient estimate is -0.18 with robust $t$ statistics of -4.55 and $R^{2}$ of 0.07 . The estimate implies that forecasters translate a 100 basis point increase in the term spread with about a 18 basis point decrease in the future policy rate, irrespective of what inflation and the unemployment rate are forecasted to be.

The dashed line in Figure 4 plots the residuals that are fitted to the term spread. The fit is reasonably good at a business cycle frequency during the 2000s until the Crisis. Thereafter, the fitted values give a much rougher fit to the residuals. We find this interesting because one

\footnotetext{
${ }^{11}$ We also ran a regression of the residuals on nowcasts of unemployment and inflation (as well as their forecasts) to check if the shifts reflect economic conditions at the time of the forecasts or dynamic adjustment. The coefficients were statistically insignificant with minimal variation explained.

${ }^{12}$ We are careful here to measure the term spread in the month before the survey month, since the economic indicator survey is collected during the first few days of the month it is released, therefore the prior month's bond prices are what is known to survey respondents at the time they report their forecasts.
} 
of the Fed's unconventional policy responses (including large-scale asset purchases) during the ZLB period has been to target medium-maturity treasuries, directly affecting the term spread. One explanation is that prior to the Crisis our policy residuals are indeed capturing the market's perceived risk. Then the term-spread might fail to capture the residuals' movement because it has become a direct tool of monetary policy since the Global Financial Crisis.

We also tried using the CME's VIX index to proxy for financial market conditions. A regression of the residuals on the VIX is statistically insignificant, and there is essentially no link between the VIX and the policy residuals. This is perhaps unsurprising given Atkeson and Kehoe's (2009) argument that the Fed responds to risk chiefly at a business cycle frequency, not to high-frequency financial market conditions - it may be that the VIX largely captures financial market conditions to which the Fed does not respond. ${ }^{13}$

This analysis supports Atkeson and Kehoe's (2009) argument that monetary policy responds to financial risk over the business cycle. Market participants form forecasts approximately by taking this argument on board. There is evidence that forecasters perceive short-rate policy as responsive to inflation, real activity, and business-cycle-frequency financial risk.

\section{Conclusion}

It is crucial to policymakers that they understand how their behavior is perceived by financial markets. Given the still-ongoing Global Financial Crisis, it is quite natural to ask: Has policymakers' behavior, or markets' perceptions thereof, changed? But the conventional

\footnotetext{
${ }^{13} \mathrm{We}$ also used the expected term premium but it was statistically insignificant. This makes sense if forecasters think that future short rates respond to past risk conditions by lowering future term premia.
} 
method of empirically answering this question is unavailable because short rates are censored due to the zero lower bound. We get around this hurdle by using surveys of professional forecasters. The surveys allows us to use a simple regression to estimate the policy rule that has prevailed - at least in professional forecasters' perception-since the onset of the Global Financial Crisis, and we find that this policy rule is significantly different from the one prevailing prior to the Global Financial Crisis.

We find that the Fed's inflation response has significantly fallen. This could portend troublesome times ahead when the Fed does start to combat inflation in some future, or instead this could reflect the success of the Fed's expansionary forward guidance that "a highly accommodative stance of monetary policy will remain appropriate for a considerable time after the economic recovery strengthens." Meanwhile, the Fed's response to unemployment has remained strong throughout the pre- and post-Crisis periods. Furthermore, we find evidence that the Federal Reserve responds to business-cycle frequency risk in addition to inflation and unemployment. 


\section{References}

Ang, Andrew, Geert Bekaert, and Min Wei. 2007. "Do macro variables, asset markets, or surveys forecast inflation better?" Journal of Monetary Economics, 54(4): 1163-1212.

Ang, Andrew, Jean Boivin, Sen Dong, and Rudy Loo-Kung. 2011. "Monetary Policy Shifts and the Term Structure." Review of Economic Studies, 78(2): 429-457.

Bernanke, Ben S., and Vincent R. Reinhart. 2004. "Conducting Monetary Policy at Very Low Short-Term Interest Rates." American Economic Review, 94(2): 85-90.

Carvalho, Carlos, and Fernanda Nechio. 2012. "Do People Understand Monetary Policy?" Federal Reserve Bank of San Francisco Working Paper Series 2012-02.

Clarida, Richard, Jordi Gali, and Mark Gertler. 2000. "Monetary Policy Rules And Macroeconomic Stability: Evidence And Some Theory." Quarterly Journal of Economics, 115(1): 147-180.

Coibion, Olivier, and Yuriy Gorodnichenko. 2012. "What Can Survey Forecasts Tell Us about Information Rigidities?" Journal of Political Economy, 120(1): 116 - 159.

Curdia, Vasco, and Michael Woodford. 2011. "The central-bank balance sheet as an instrument of monetary policy." Journal of Monetary Economics, 58(1): 54-79.

Devereux, Michael B., Gregor W. Smith, and James Yetman. 2012. "Consumption and real exchange rates in professional forecasts." Journal of International Economics, 86(1): $33-42$. 
Engelberg, Jospeh, Charles F. Manski, and Jared Williams. 2011. "Assessing the temporal variation of macroeconomic forecasts by a panel of changing composition." Journal of Applied Econometrics, 21: 1059-1078.

Fendel, Ralf, Michael Frenkel, and Jan-Christoph Rulke. 2011. "“Ex-ante” Taylor rules and expectation forming in emerging markets." Journal of Comparative Economics, 39: 230-244.

Gerlach, Stefan, and John Lewis. 2011. "ECB reaction functions and the crisis of 2008." Centre for Economic Policy Research.

Hamilton, James D., Seth Pruitt, and Scott Borger. 2011. "Estimating the MarketPerceived Monetary Policy Rule." American Economic Journal: Macroeconomics, $3(3): 1-28$.

Hirose, Yasuo, and Takushi Kurozumi. 2012. "Identifying News Shocks with Forecast Data." Australian National University.

Kim, Jinill, and Seth Pruitt. 2013. "Estimating Monetary Policy Rules When Nominal Interest Rates Are Stuck at Zero." CAMA Working Paper.

Mitchell, Karlyn, and Douglas K. Pearce. 2010. "Do Wall Street economists believe in Okun's Law and the Taylor Rule?" Journal of Economics \&3 Finance, 34: 196-217.

Romer, Christina D, and David H Romer. 2000. "Federal Reserve Information and the Behavior of Interest Rates." American Economic Review, 90(3): 429-457. 
Rudebusch, Glenn D. 2009. "The Fed's monetary policy response to the current crisis." FRBSF Economic Letter, 17.

Swanson, Eric T, and John Williams. forthcoming. "Measuring the Effect of the Zero Lower Bound on Medium- and Longer-Term Interest Rates." American Economic Review.

Taylor, John B. 1993. "Discretion versus Policy Rules in Practice." Carnegie-Rochester Conference Series on Public Policy, XXXIX: 195-214. 